Research Article

\title{
Safety and Efficacy of Cryoballoon Ablation of Atrial Fibrillation in relation to the Patients' Age: Results from a Large Real-World Multicenter Observational Project
}

\author{
Luigi Sciarra ${ }^{1 D},{ }^{1}$ Saverio Iacopino, ${ }^{2}$ Giuseppe Arena, ${ }^{3}$ Claudio Tondo, ${ }^{4}$ Paolo Pieragnoli, ${ }^{5}$ \\ Giulio Molon, ${ }^{6}$ Massimiliano Manfrin, ${ }^{7}$ Antonio Curnis, ${ }^{8}$ Antonio Dello Russo, ${ }^{9}$ \\ Giovanni Rovaris, ${ }^{10}$ Giuseppe Stabile, ${ }^{11}$ Leonardo Calò, ${ }^{1}$ Gabriele Boscolo, ${ }^{12}$ \\ and Roberto Verlato ${ }^{13}$ \\ ${ }^{1}$ Cardiology Department, Policlinico Casilino, Rome, Italy \\ ${ }^{2}$ Maria Cecilia Hospital, GVM CareßResearch, Cotignola (RA), Italy \\ ${ }^{3}$ Nuovo Ospedale Delle Apuane, Massa, Italy \\ ${ }^{4}$ Heart Rhythm Center at Monzino Cardiac Center, IRCC Dept. of Clinical Sciences and Community Health, University of Milan, \\ Milan, Italy \\ ${ }^{5}$ Careggi Hospital, Florence, Italy \\ ${ }^{6}$ IRCCS Sacro Cuore Don Calabria Hospital, Negrar, Verona, Italy \\ ${ }^{7}$ Ospedale Centrale di Bolzano, Divisione di Cardiologia, Bolzano, Italy \\ ${ }^{8}$ Spedali Civili, Brescia, Italy \\ ${ }^{9}$ Cardiology and Arrhythmology Clinic, Biomedical Science and Public Health Department, Polytechnic University, Ancona, Italy \\ ${ }^{10}$ Ospedale San Gerardo, Azienda Socio Sanitaria Territoriale, Monza, Italy \\ ${ }^{11}$ Clinica Montevergine Mercogliano (AV), Casa di Cura San Michele, Maddaloni (CE), Italy \\ ${ }^{12}$ Azienda ULSS 3 Ospedale di Chioggia, Chioggia, Italy \\ ${ }^{13}$ ULSS 6 Euganea, Camposampiero, Italy
}

Correspondence should be addressed to Luigi Sciarra; lui.sciarra@libero.it

Received 28 March 2021; Revised 6 December 2021; Accepted 8 December 2021; Published 28 December 2021

Academic Editor: Eduard Guasch

Copyright (C) 2021 Luigi Sciarra et al. This is an open access article distributed under the Creative Commons Attribution License, which permits unrestricted use, distribution, and reproduction in any medium, provided the original work is properly cited.

Background. The real-world efficacy and safety of atrial fibrillation (AF) ablation in particularly young and elderly patients are still under debate. The aim of the analysis was to investigate the effect of age on the efficacy and safety of cryoballoon ablation (CBA). Methods. 2,534 patients underwent pulmonary vein isolation (PVI) by way of CBA for paroxysmal or persistent drug-resistant and symptomatic AF. The population was divided into age quartiles for evaluation, including (1) $<53$ years, (2) $\geq 53$ and $<61$ years, (3) $\geq 61$ and $<67$ years, and $(4) \geq 67$ years. Furthermore, outcomes were analyzed in patients $<41$ years, $\geq 41$ and $\leq 74$, and $>74$ years old. Procedural data and complications were collected, and atrial fibrillation recurrences were evaluated during follow-up. Results. Procedural-related complications (4.1\%) were similar in the four subgroups according to age. At the 12-month follow-up, freedom from AF recurrence was 79.2\%, 77.4\%, 76.8\%, and 75.2\% ( $p=0.21$ ), respectively (with increasing age). At 24-month follow-up, similar incidences of AF recurrence were observed in the four subgroups. When the sample was arbitrarily divided into the three age groups, a higher rate of recurrence was observed in older patients with regard to long-term follow-up (freedom from AF recurrence was $71.8 \%$ and $40.9 \%$, respectively, at 12 and 24-month follow-up). In the univariate and multivariate analysis, age did not result in a significant predictor of $\mathrm{AF}$ recurrence during follow-up; however, a trend toward higher $\mathrm{AF}$ recurrences rates in patients $\geq 67$ years was observed. Conclusion. The data demonstrated a high degree of safety during CBA across all patient ages. Procedural performance and complications were similar between different ages; AF recurrences seem to be more frequent in patients over 74 years. 


\section{Introduction}

Atrial fibrillation (AF) is the most common sustained arrhythmia encountered in clinical practice [1]. The prevalence of arrhythmia is about $2 \%$ in the general population, and it significantly increases with age [1-4]. It has been observed that AF prevalence is between $10 \%$ and $17 \%$ in people aged 80 years or older [5]. In view of the increased life expectancy in the developed world, AF in the elderly becomes a significant public health problem $[4,5]$. Moreover, AF has been correlated to increased morbidity and mortality, particularly in older patients $[4,5]$.

Catheter ablation has emerged as a cornerstone in the treatment of atrial arrhythmia with a good benefit-to-risk ratio, particularly in patients with drug-refractory symptomatic AF [6-13]. To date, many ablative schemes have been proposed, but strategies that target the pulmonary veins (PVs) are the cornerstone for most ablative procedures [14-16]. In order to simplify ablative techniques for pulmonary vein isolation (PVI), several "one-shot" devices have been proposed. Among these novel devices, cryoballoon ablation (CBA) of PVs has been widely used, and the efficacy and safety have been comparable to point-by-point radiofrequency ablation (RFA), in prospective randomized trials $[17,18]$. Therefore, for the first time, the ESC guidelines on AF management published in 2016 indicated PVI by RFA or CBA without preference [19].

The efficacy and safety of catheter ablation of AF in the elderly population have not been deeply investigated, and older patients are often not represented in clinical trials, due in part to age-based inclusion and exclusion criteria. However, such a population could particularly benefit from AF ablation from a theoretical point of view. Conversely, older patients are more likely to have comorbidities that could increase the risks of ablative procedures. Additionally, the benefit of catheter ablation in terms of safety and efficacy in young adults has not been demonstrated in a large cohort study. Consequently, the aim of this analysis was to investigate the safety and efficacy of CBA among patients with $\mathrm{AF}$ in a large population collected in a multicenter realworld project. Specifically, this analysis evaluated quartiles of patient age during a CBA procedure using a PVI strategy of ablation with the specific aim of examining the potential differences in response for the young and old patients with regard to efficacy and safety.

\section{Methods}

From April 2012 to September 2018, consecutive patients suffering from recurrent, symptomatic, and drug-refractory AF underwent an index PVI procedure with the cryoballoon (Arctic Front or Arctic Front Advance; Medtronic, Inc.) in 47 Italian centers participating in the One-Shot TO Pulmonary vein isolation (1STOP) ClinicalService ${ }^{\circledR}$ project. Exclusion criteria were as follows: (1) permanent AF, (2) previous catheter ablation of AF, (3) New York Heart Association functional class IV, (4) unstable angina or acute myocardial infarction within three months, (5) need for or prior cardiac surgery within six months, and (6) contraindication to treatment with oral anticoagulants. Patients were prospectively followed up according to each center's clinical practice through standard in-hospital visits, remote monitoring reports, and/or telephonic visits. ClinicalService ${ }^{\circledR}$ is a national cardiovascular data repository and medical care project designed to describe and improve the quality of diagnostic and therapeutic strategies using technologies and therapies in the Italian clinical practice [20, 21]. A charter assigns the ownership of data to the participating centers and governs the conduct and relationship of the scientific committee and Medtronic. During this project, Medtronic did not have any role in identifying research objectives, interpreting results, or drafting the original manuscript. This project was approved by each site's Institutional Review Board and Local Ethics Committees. The design conforms to the principles outlined in the 1975 Declaration of Helsinki as reflected in the a priori approval by the institution's human research committee. Each patient included in the ClinicalService ${ }^{\circledR}$ project provided informed consent for the data collection and analysis.

The objective of this research was to assess whether procedural times, procedure-related complications, and AF recurrences differed according to the patients' age group when evaluated in quartiles. Quartiles have been defined according to the years of age of the study population (Supplementary Figure 1). In summary, the primary safety endpoint was procedural-related complications that occurred during the catheter ablation procedure or after the ablative procedure. The primary efficacy endpoint was the recurrence of $\mathrm{AF}$, defined as the detection of AF both symptomatic and asymptomatic (at least $30 \mathrm{sec}$ in duration when assessed with ECG monitoring) after a landmark 90day blanking period. Before reviewing the data, the physician committee predefined the primary safety and efficacy endpoints, and the physician committee chose to divide the population into four groups according to the statistical distribution of quartiles in age at the index ablation, including $(1)<53$ years, $(2) \geq 53$ and $<61$ years, $(3) \geq 61$ and $<67$ years, and $(4) \geq 67$ years.

2.1. Subanalysis (Three Age Group Analysis). Also, the committee decided to present the efficacy and safety outcomes in patients $<41$ years (defined as "very young" patients group) and in patients $>74$ (defined as "very old" patients group). This second grouping of patients (Supplementary Figure 1) was arbitrary and conducted in order to examine data from a cohort of patients that are underrepresented in the published literature.

2.2. Ablative Procedure. The CBA procedure has been previously described in detail $[22,23]$. Each center utilized its own standard-of-care practices and approaches during the cryoablation procedure. In general, subjects were treated under general anesthesia or conscious sedation. A 
transseptal needle puncture for left atrial access was immediately followed by a heparin bolus delivery, and the subsequent heparin delivery was administered while monitoring the activated clotting time. Most often, a purposebuilt dedicated delivery sheath (FlexCath, Medtronic, Inc.) was used to advance the balloon catheter and guidewire assembly during the ablation procedure. CBA procedures were performed with a $23 \mathrm{~mm}$ and/or $28 \mathrm{~mm}$ cryoballoon, which was delivered by an over-the-wire method into the left atrium. The number of freeze applications and the length of individual freezes were determined by the hospital standardof-care usage. In addition, postablation testing methods were left to the discretion of the physician operator; however, acute PVI was the intraprocedural efficacy endpoint, which was consistently defined as electrical conduction isolation confirmed by bidirectional block. In general, acute PVI was assessed using the dedicated balloon inner-lumen diagnostic mapping catheter (Achieve mapping catheter, Medtronic, Inc.) and/or a lasso style circular diagnostic mapping catheter.

2.3. Data Collection and Follow-Up. Routine follow-up assessments were conducted in accordance with the standard of care and clinical practice of the participating centers by means of hospital visits and/or telephone interviews. Followup visits were scheduled for every 3 months after the index CBA procedure during the first 12 -month period of followup (after the index ablation procedure). Each follow-up examination included an AF-related symptoms review, electrocardiography (ECG) for arrhythmic event assessment, and Holter monitoring according to the clinical practice. Patients were asked to provide any additional Holter or ECG records since the previous visit. The management of antiarrhythmic drugs (AADs) was left to the clinical practice of each center. After the 12-month visit, subject follow-up was performed every 6 months. If subjects missed their scheduled follow-up visit, they or their relatives were contacted by telephone. After two unsuccessful attempts at phone contact, information on the patient's life status was collected from the National Office of Vital Statistics (Italy). The first 90 days after AF ablation were denoted as the "landmark" blanking period during which no efficacy endpoint failures were calculated to allow for postablation healing without penalty to the efficacy endpoint assessment [24]. Thereafter, during the efficacy follow-up assessment, recurrence of atrial arrhythmia was defined as the detection of AF (at least 30 seconds in duration by ECG monitoring) after the performance of a single CBA procedure, with or without the use of AADs. All reported procedural-related complications were recorded, and adverse event classifications of minor or major events were made in accordance with previously published worldwide surveys on AF ablation.

2.4. Statistical Analysis. Descriptive statistics were used to summarize patient characteristics. These data include mean, standard deviation, minimum, maximum, and median with the interquartile range for continuous variables. Categorical variables were described by counts and percentages. Summary statistics were reported with a maximum of two decimals, as appropriate. Comparisons between groups have been performed using Kruskal Wallis's Test for continuous variables, while comparisons of categorical variables have been performed by means of the Chi-square test. Statistical tests were based on a two-sided significance level of 0.05 . The analyses of time-to-the-first event were described by means of Kaplan-Meier curves and compared between the groups (two-by-two) by means of the adjusted Log-Rank Test. The follow-up duration (in months) has been computed from the date of the index ablation procedure to the date of the last available follow-up or the date of the efficacy failure event. The annual rates of complications were reported, together with the 95\% Poisson Confidence Intervals. The Poisson regression model was used to calculate the incidence rate ratio (IRR), with the d-scale option. An IRR $<1$ would show a higher incidence of event in the reference group, while an IRR $>1$ would show a lower incidence of event in the reference group. Cox regression was used in both univariate and multivariate analyses to detect predictors for AF recurrences. Parameters that were significant from the univariate analysis $(p<0.10)$ were analyzed in a multivariate model, with a stepwise selection. Variables were kept in the model if they were significant $(p<0.05)$. The Cox model prediction performance was assessed using discrimination, and the C-index was reported.

The SAS software, version 9.4 (SAS Institute Inc., Cary, NC, USA), was used to perform statistical analyses.

\section{Results}

3.1. Baseline Characteristic. During this 1 STOP analysis, a total of 2,534 patients underwent an index PVI by CBA. Baseline characteristics of the patient population are summarized in Table 1, and the total sample was divided into four groups according to the statistical distribution by quartiles (of age) at the time of index CBA. Trends about quartiles of age distribution over enrolling years are presented in Figure 1.

In the three age groups subanalysis, the study population has been arbitrarily divided into three clinically relevant groups, including the "very young" patient group (131 patients; age $\leq 40$ years), intermediate age group $(2,281$ patients; age $>40$ and $<75$ years), and "very old" patients (122 patients; age $\geq 75$ years).

\subsection{Clinical Outcomes: Procedural Data and Complications.} Procedural data and complications are summarized in Tables 2 and 3. Within the quartile analyses (Table 2), procedural duration, fluoroscopy time exposure, and left atrial dwell time were comparable between the four cohorts with no statistical difference between groups. Only $2.3 \%$ of the patients were treated using $2.3 \mathrm{~mm}$ cryoballoon according to the operator's judgment. The percentage of successfully isolated PVs was slightly but significantly lower in the younger group when compared to the other three 
TABLE 1: Baseline patient characteristics $(N=2534)$ by quartiles.

\begin{tabular}{|c|c|c|c|c|c|c|}
\hline Baseline characteristics & $\begin{array}{l}\text { Total cohort } \\
(N=2534)\end{array}$ & $\begin{array}{c}\text { Age } \\
<53 \\
(N=584)\end{array}$ & $\begin{array}{c}\text { Age } \\
\geq 53 \text { and }<61 \\
(N=630)\end{array}$ & $\begin{array}{c}\text { Age } \\
\geq 61 \text { and }<67 \\
(N=594)\end{array}$ & $\begin{array}{l}\text { Age } \geq 67 \\
(N=726)\end{array}$ & $p$ value \\
\hline Age at first ablation (years) & $59.7 \pm 10.5$ & $44.8 \pm 6.7$ & $56.7 \pm 2.3$ & $63.6 \pm 1.7$ & $71.1 \pm 3.5$ & $<0.001^{1,2,3,4,5,6}$ \\
\hline Gender (female) & $27.4 \%(695)$ & $17.8 \%(104)$ & $22.2 \%(140)$ & $30.1 \%(179)$ & $37.5 \%(272)$ & $<0.0011^{1,2,3,4,5,6}$ \\
\hline Body Mass index & $27.0 \pm 4.1$ & $26.8 \pm 4.4$ & $27.6 \pm 4.3$ & $26.8 \pm 3.9$ & $26.8 \pm 4.0$ & $0.005^{1,4,5}$ \\
\hline Any arrhythmia symptoms & $88.9 \%(2253)$ & $88.9 \%(519)$ & $89.2 \%(562)$ & $90.1 \%(535)$ & $87.7 \%(637)$ & 1.000 \\
\hline Type of atrial fibrillation (AF) & & & & & & $0.847^{*}$ \\
\hline Paroxysmal & $74.9 \%(1899)$ & $79.3 \%(463)$ & $74.9 \%(472)$ & $72.4 \%(430)$ & $73.6 \%(534)$ & \\
\hline Persistent & $22.6 \%(572)$ & $19.0 \%(111)$ & $22.5 \%(142)$ & $25.1 \%(149)$ & $23.4 \%(170)$ & \\
\hline Long-standing persistent & $2.5 \%(63)$ & $1.7 \%(10)$ & $2.5 \%(16)$ & $2.5 \%(15)$ & $3.0 \%(22)$ & \\
\hline Months from first AF diagnosis & $55.0 \pm 106.2$ & $45.2 \pm 54.7$ & $50.9 \pm 102.3$ & $60.6 \pm 141.2$ & $62.0 \pm 107.1$ & $0.004^{3}$ \\
\hline Failed $\geq 2$ antiarrhythmic drugs & $43.6 \%(1106)$ & $32.6 \%(190)$ & $42.6 \%(268)$ & $49.0 \%(291)$ & $49.3 \%(357)$ & $<0.001^{1,2,3,4,5}$ \\
\hline New York heart association class & & & & & & $0.003 *^{1,2,3,5}$ \\
\hline 1 & 78.9\% (1999) & $85.4 \%(499)$ & $80.0 \%(504)$ & $79.1 \%(470)$ & $72.3 \%(525)$ & \\
\hline$\geq 2$ & $21.1 \%(535)$ & $14.6 \%(85)$ & $20 \%(126)$ & $20.9 \%(124)$ & $27.7 \%(201)$ & \\
\hline History of Stroke/TIA & $4.6 \%(116)$ & $2.3 \%(13)$ & $4.8 \%(30)$ & $4.4 \%(26)$ & $6.4 \%(47)$ & $0.039^{1,2,3}$ \\
\hline Cardiac insufficiency & $3.9 \%(99)$ & $4.0 \%(24)$ & $3.7 \%(23)$ & $3.4 \%(20)$ & $4.2 \%(32)$ & 1.000 \\
\hline Hypertension & $47.8 \%(1198)$ & $27.3 \%(158)$ & $45.3 \%(282)$ & $52.0 \%(307)$ & $62.8 \%(451)$ & $<0.001^{1,2,3,4,5,6}$ \\
\hline Any valve disease & $5.4 \%(137)$ & $4.2 \%(24)$ & $4.3 \%(28)$ & $4.1 \%(24)$ & $8.4 \%(61)$ & $0.003^{3,5,6}$ \\
\hline $\mathrm{CHA}_{2} \mathrm{DS}_{2}$-VASc score & & & & & & $<0.001 *^{1,2,3,4,5,6}$ \\
\hline 0 & $23.3 \%(590)$ & $54.0 \%(316)$ & $36.2 \%(228)$ & $7.8 \%(46)$ & $0.0 \%(0)$ & \\
\hline 1 & $30.6 \%(775)$ & $37.4 \%(219)$ & $41.7 \%(262)$ & $34.3 \%(203)$ & $12.4 \%(90)$ & \\
\hline 2 & $24.5 \%(620)$ & $6.0 \%(35)$ & $17.6 \%(110)$ & $37.0 \%(220)$ & $35.0 \%(255)$ & \\
\hline 3 & $21.6 \%(549)$ & $2.3 \%(14)$ & $4.7 \%(29)$ & $21.0 \%(125)$ & $52.4 \%(381)$ & \\
\hline Diabetes & $5.4 \%(137)$ & $3.7 \%(22)$ & $4.8 \%(30)$ & $5.5 \%(33)$ & $7.2 \%(52)$ & 0.376 \\
\hline Chronic renal failure & $2.3 \%(58)$ & $0.0 \%(0)$ & $1.4 \%(9)$ & $3.1 \%(18)$ & $4.4 \%(31)$ & $<0.001^{1,2,3,5}$ \\
\hline Ischemic cardiopathy & $6.0 \%(153)$ & $1.7 \%(10)$ & $3.9 \%(24)$ & $8.1 \%(47)$ & $9.7 \%(69)$ & $<0.001^{1,2,3,4,5}$ \\
\hline Hypertensive cardiopathy & $15.8 \%(401)$ & $8.2 \%(48)$ & $15.1 \%(95)$ & $15.0 \%(89)$ & $23.3 \%(169)$ & $<0.001^{1,2,3,5,6}$ \\
\hline Primitive cardiomyopathy & $3.3 \%(84)$ & $4.1 \%(24)$ & $4.2 \%(27)$ & $3.0 \%(18)$ & $2.0 \%(15)$ & 0.618 \\
\hline $\begin{array}{l}\text { Left ventricular ejection fraction } \\
(\%)\end{array}$ & $59.2 \pm 7.0$ & $59.1 \pm 7.5$ & $59.6 \pm 6.6$ & $59.3 \pm 6.7$ & $58.8 \pm 7.2$ & 0.570 \\
\hline Left atrial area $\left(\mathrm{cm}^{2}\right)$ & $22.1 \pm 6.1$ & $20.7 \pm 5.0$ & $22.2 \pm 7.3$ & $22.6 \pm 5.2$ & $22.9 \pm 6.2$ & $<0.001^{1,2,3}$ \\
\hline Antiarrhythmic drug usage & $71.8 \%(1819)$ & $70.0 \%(408)$ & $72.5 \%(457)$ & $73.9 \%(439)$ & $71.0 \%(515)$ & 1.000 \\
\hline Anticoagulant therapy usage & $82.9 \%(2100)$ & $72.2 \%(422)$ & $82.3 \%(519)$ & $86.3 \%(514)$ & $88.8 \%(645)$ & 0.570 \\
\hline
\end{tabular}

${ }^{1}$ A significant difference between age $<53$ and age $\geq 53$ and $<61 ;{ }^{2}$ a significant difference between age $<53$ and age $\geq 61$ and $<67 ;{ }^{3}$ a significant difference between age $<53$ and age $\geq 67 ;{ }^{4}$ a significant difference between age $\geq 53$ and $<61$ and age $\geq 61$ and $<67 ;{ }^{5}$ a significant difference between age $\geq 53$ and $<61$ and $a g e \geq 67 ;{ }^{6}$ a significant difference between age $\geq 61$ and $<67$ and age $\geq 67$. The $p$ was referred to as the differences in group distribution.

groups $(p<0.001)$. Complication rates were comparable in the four groups studied.

3.3. Clinical Outcomes: AF Recurrences in Follow-Up. The mean follow-up of the cohort of patients was $15.3 \pm 14.7$ months. The minimum follow-up duration was 3 months, and the maximum follow-up duration was 67.1 months. No significant differences were observed between different age groups. During follow-up, 613 (24.2\%) patients had at least one AF recurrence episode. The analysis of the four subgroups (dividing population according to the statistical distribution of quartiles in age at index ablation) did not show any significant difference in terms of AF recurrences (Figure 2). In particular, the annual rate of AF recurrence was $17.5 \%$ (95\% CI: 14.8\%-20.7\%), 17.9\% (95\%CI: $15.2 \%-$ $21.1 \%$ ), $17.69 \%$ (95\%CI: $14.9 \%-21.0 \%$ ), and 21.04 (95\% CI: $18.2 \%-24.3 \%)$ in the four groups increasing in age, respectively. Also, the unadjusted survival analysis for the freedom from AF recurrence (Figure 2 panel a) showed no statistical difference between the groups. The 1-year survival probability was $79.2 \pm 3.5 \%, 77.4 \pm 4.3 \%, 76.8 \pm 4.7 \%$, and $75.2 \pm 4.6 \%$ in the four quartiles, respectively $(p=0.390)$. During the follow-up, 153 patients (6.0\%) underwent a repeat procedure, including $50(8.6 \%)$ in the age $<53$ group, $46(7.3 \%)$ in the $53-61$ age group, $28(4.7 \%)$ in the $61-67$ age group, and $29(4.0 \%)$ in the age $\geq 67$ group $(p=0.009)$.

In univariate (Table 4 ) and multivariate analysis, many baseline predictors were tested to find a possible correlation with AF recurrences in follow-up. Baseline characteristics resulting in differences between groups were tested, and no significant correlation between age groups and AF recurrence was found. Even in the multivariate analysis, there was no correlation between age and AF recurrences. However, a nonstatistically significant trend toward higher AF recurrences rates in patients $\geq 67$ years was observed. In the multivariate model, persistent $\mathrm{AF}$ and $\mathrm{CHA}_{2} \mathrm{DS}_{2}$-VASc resulted to be independent predictors of AF recurrences (see Table 4). 
Frequency of Age classes by Implant Year

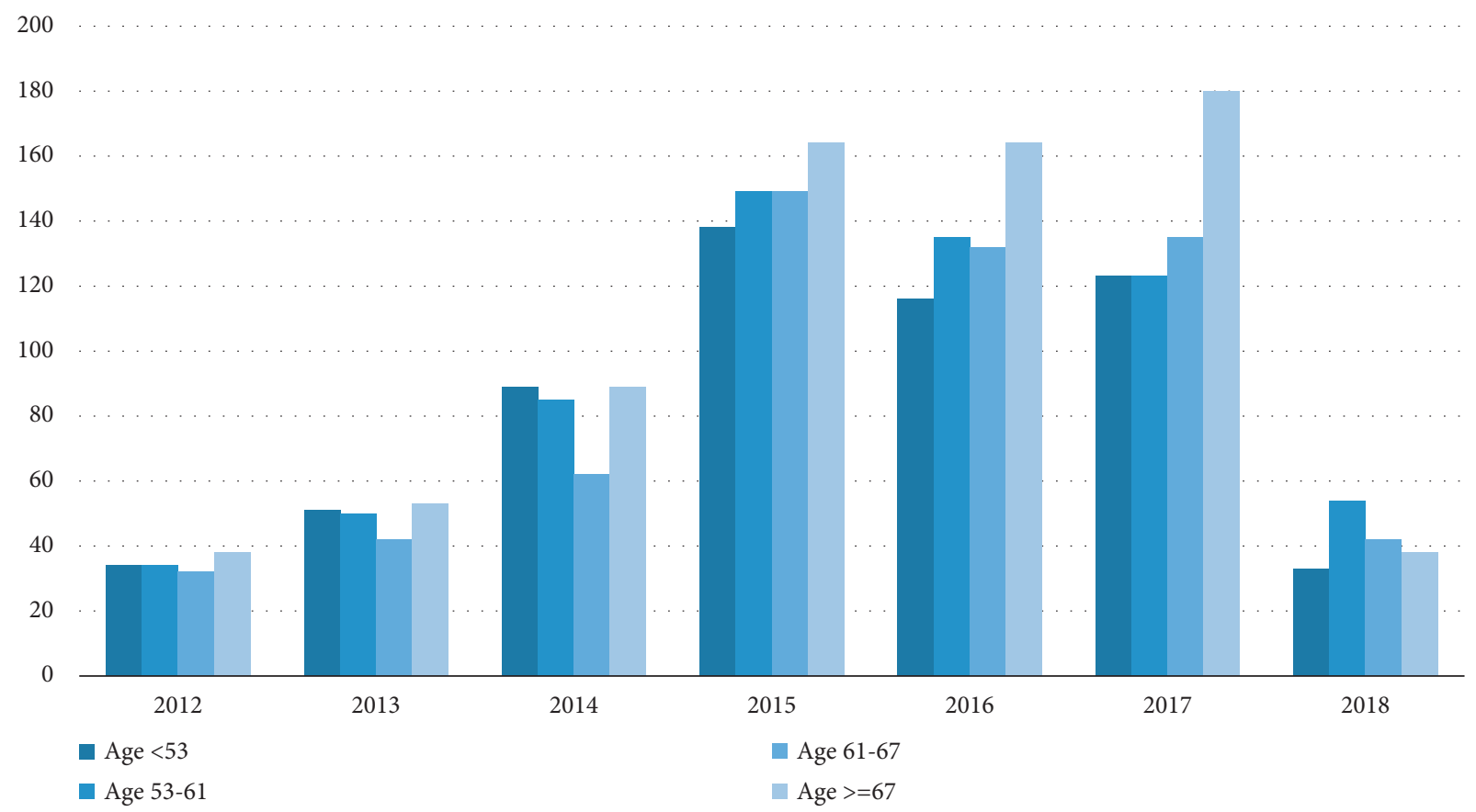

FIGURE 1: Quartiles of age distribution over enrolling years are presented. A trend toward wider indications in patients $\geq 67$ years between 2015 and 2017 can be appreciated. However, no statistically significant differences were found in terms of age distribution ( $p=0.567)$. Data of 2018 were not analyzed, since the database freeze was performed in September 2018.

TABle 2: Procedural and safety characteristics $(N=2534)$ by age groups divided into quartiles.

\begin{tabular}{|c|c|c|c|c|c|c|}
\hline Procedural characteristics & $\begin{array}{c}\text { TOTAL } \\
(n=2534)\end{array}$ & $\begin{array}{l}\text { Age }<53 \\
(n=584)\end{array}$ & $\begin{array}{c}\text { Age 53-61 } \\
(n=630)\end{array}$ & $\begin{array}{c}\text { Age 61-67 } \\
(n=594)\end{array}$ & $\begin{array}{l}\text { Age } \geq 67 \\
(n=726)\end{array}$ & $p$ value \\
\hline Procedure duration (min) & $106.2 \pm 46.5$ & $110.0 \pm 49.6$ & $108.1 \pm 45.8$ & $104.0 \pm 45.2$ & $103.4 \pm 45.3$ & 0.064 \\
\hline Fluoroscopy time (min) & $28.5 \pm 27.4$ & $28.5 \pm 14.7$ & $29.8 \pm 48.0$ & $27.8 \pm 15.7$ & $28.0 \pm 15.5$ & 1.000 \\
\hline Ablation time (min) & $25.0 \pm 17.5$ & $26.0 \pm 19.1$ & $26.0 \pm 17.2$ & $23.9 \pm 16.7$ & $24.1 \pm 17.0$ & $0.025^{4,5}$ \\
\hline $\begin{array}{l}\% \text { Of isolated PVs ( } n \text { treated veins } / n \\
\text { target veins) }\end{array}$ & $\begin{array}{c}98.1 \% \\
(9547 / 9729)\end{array}$ & $\begin{array}{c}96.7 \% \\
(2200 / 2269)\end{array}$ & $\begin{array}{c}98.6 \% \\
(2371 / 2404)\end{array}$ & $\begin{array}{c}98.3 \% \\
(2222 / 2261)\end{array}$ & $\begin{array}{c}98.5 \% \\
(2754 / 2795)\end{array}$ & $<0.001^{1,2,3}$ \\
\hline Left atrium dwell time (min) & $57.0 \pm 26.7$ & $59.8 \pm 28.5$ & $58.1 \pm 27.2$ & $55.9 \pm 26.0$ & $54.8 \pm 25.1$ & 0.150 \\
\hline $\begin{array}{l}\text { Patients with at least one } \\
\text { complication }\end{array}$ & $4.1 \%(104)$ & $3.8 \%(22)$ & $3.8 \%(24)$ & $4.0 \%(24)$ & $4.7 \%(34)$ & 1.000 \\
\hline Permanent diaphragmatic paralysis & $0.0 \%(1)$ & $0.2 \%(1)$ & $0.0 \%(0)$ & $0.0 \%(0)$ & $0.0 \%(0)$ & 1.000 \\
\hline Transient diaphragmatic paralysis & $1.8 \%(46)$ & $1.5 \%(9)$ & $2.2 \%(14)$ & $1.9 \%(11)$ & $1.7 \%(12)$ & 1.000 \\
\hline Pericardial effusion & $0.2 \%(6)$ & $0.3 \%(2)$ & $0.0 \%(0)$ & $0.0 \%(0)$ & $0.6 \%(4)$ & 0.610 \\
\hline Femoral arterio-venous fistula & $0.3 \%(7)$ & $0.5 \%(3)$ & $0.0 \%(0)$ & $0.2 \%(1)$ & $0.4 \%(3)$ & 1.000 \\
\hline Cardiac tamponade & $0.3 \%(7)$ & $0.2 \%(1)$ & $0.2 \%(1)$ & $0.3 \%(2)$ & $0.4 \%(3)$ & 1.000 \\
\hline Pneumothorax/Hemothorax & $0.0 \%(0)$ & $0.0 \%(0)$ & $0.0 \%(0)$ & $0.0 \%(0)$ & $0.0 \%(0)$ & - \\
\hline Femoral pseudoaneurism & $0.1 \%(3)$ & $0.0 \%(0)$ & $0.2 \%(1)$ & $0.2 \%(1)$ & $0.1 \%(1)$ & 1.000 \\
\hline TIA & $0.2 \%(3)$ & $0.0 \%(0)$ & $0.2 \%(1)$ & $0.0 \%(0)$ & $0.1 \%(2)$ & 1.000 \\
\hline Hematoma & $0.4 \%(9)$ & $0.2 \%(1)$ & $0.3 \%(2)$ & $0.5 \%(3)$ & $0.4 \%(3)$ & 1.000 \\
\hline Other complication & $0.9 \%(22)$ & $0.9 \%(5)$ & $0.8 \%(5)$ & $1.0 \%(6)$ & $1.0 \%(6)$ & 1.000 \\
\hline
\end{tabular}

${ }^{1}$ A significant difference between age $<53$ and age $\geq 53$ and $<61 ;{ }^{2}$ a significant difference between age $<53$ and age $\geq 61$ and $<67 ;{ }^{3}$ a significant difference between age $<53$ and age $\geq 67 ;{ }^{4}$ a significant difference between age $\geq 53$ and $<61$ and age $\geq 61$ and $<67 ;{ }^{5}$ a significant difference between age $\geq 53$ and $<61$ and $a g e \geq 67 ;{ }^{6}$ a significant difference between age $\geq 61$ and $<67$ and ag $e \geq 67$.

3.4. Three Age Groups Subanalysis. When analyzed by the three clinically relevant age groups (Table 3), there were no differences in all procedural parameters. The proceduralrelated complications were similar between all groups.

When considering the analysis dividing patients into three groups (very young, intermediate age, and very old patients), an increased rate of AF recurrences was observed in patients over 74 years. The 1-year freedom from AF recurrence probability was $83.1 \%$ in patients $<41$ years, $77.0 \%$ in the intermediate age patients, and $71.8 \%$ in patients with more than 74 years, $p=0.038$ (Figure 2, panel b). Twelve patients $(9.2 \%)$ in younger, $135(5.9 \%)$ in the intermediate and $6(4.9 \%)$ in the older patient groups underwent redo procedure $(p=0.826)$. 
TABle 3: Procedural and safety characteristics $(N=2534)$ by three age groups.

\begin{tabular}{|c|c|c|c|c|c|}
\hline Procedural characteristics & $\begin{array}{c}\text { Total } \\
(n=2534)\end{array}$ & $\begin{array}{c}\text { "Very young" } \\
\text { Age } \leq 40 \\
(n=131)\end{array}$ & $\begin{array}{c}\text { "Intermediate age" } \\
\text { Age 41-74 } \\
(n=2281)\end{array}$ & $\begin{array}{l}\text { "Very old" } \\
\text { Age } \geq 75 \\
(n=122) \\
\end{array}$ & $p$ value \\
\hline Procedure duration (min) & $106.2 \pm 46.5$ & $101.3 \pm 43.3$ & $107.0 \pm 46.9$ & $97.6 \pm 41.3$ & 0.124 \\
\hline Fluoroscopy duration (min) & $28.5 \pm 27.4$ & $26.0 \pm 13.3$ & $28.8 \pm 28.5$ & $25.4 \pm 12.1$ & 0.344 \\
\hline Ablation time (min) & $25.0 \pm 17.5$ & $23.5 \pm 14.6$ & $25.1 \pm 17.8$ & $23.9 \pm 15.2$ & 1.000 \\
\hline Left atrium dwell time (min) & $57.0 \pm 26.7$ & $54.7 \pm 23.3$ & $57.5 \pm 27.1$ & $51.5 \pm 20.4$ & 0.622 \\
\hline Patients with at least one complication & $4.1 \%(104)$ & $2.3 \%(3)$ & $4.3 \%(97)$ & $3.3 \%(4)$ & 1.000 \\
\hline Permanent diaphragmatic paralysis & $0.0 \%(1)$ & $0.0 \%(0)$ & $0.0 \%(1)$ & $0.0 \%(0)$ & - \\
\hline Transient diaphragmatic paralysis & $1.8 \%(46)$ & $0.8 \%(1)$ & $1.9 \%(43)$ & $1.6 \%(2)$ & 1.000 \\
\hline Pericardiac effusion & $0.2 \%(6)$ & $0.0 \%(0)$ & $0.2 \%(5)$ & $0.8 \%(1)$ & 1.000 \\
\hline Femoral arterio-venous fistula & $0.3 \%(7)$ & $0.8 \%(1)$ & $0.2 \%(5)$ & $0.8 \%(1)$ & 0.776 \\
\hline Cardiac tamponade & $0.3 \%(7)$ & $0.0 \%(0)$ & $0.3 \%(7)$ & $0.0 \%(0)$ & 1.000 \\
\hline Pneumothorax/Hemothorax & $0.0 \%(0)$ & $0.0 \%(0)$ & $0.0 \%(0)$ & $0.0 \%(0)$ & - \\
\hline Femoral pseudoaneurism & $0.1 \%(3)$ & $0.0 \%(0)$ & $0.1 \%(3)$ & $0.0 \%(0)$ & 1.000 \\
\hline Stroke & $0.0 \%(0)$ & $0.0 \%(0)$ & $0.0 \%(0)$ & $0.0 \%(0)$ & - \\
\hline TIA & $0.1 \%(3)$ & $0.0 \%(0)$ & $0.1 \%(2)$ & $0.0 \%(1)$ & 1.000 \\
\hline Pulmonary vein stenosis & $0.0 \%(0)$ & $0.0 \%(0)$ & $0.0 \%(0)$ & $0.0 \%(0)$ & - \\
\hline Hematoma & $0.4 \%(9)$ & $0.0 \%(0)$ & $0.4 \%(9)$ & $0.0 \%(0)$ & 1.000 \\
\hline Other complication & $0.9 \%(22)$ & $0.8 \%(1)$ & $1.0 \%(22)$ & $0.0 \%(0)$ & 1.000 \\
\hline
\end{tabular}

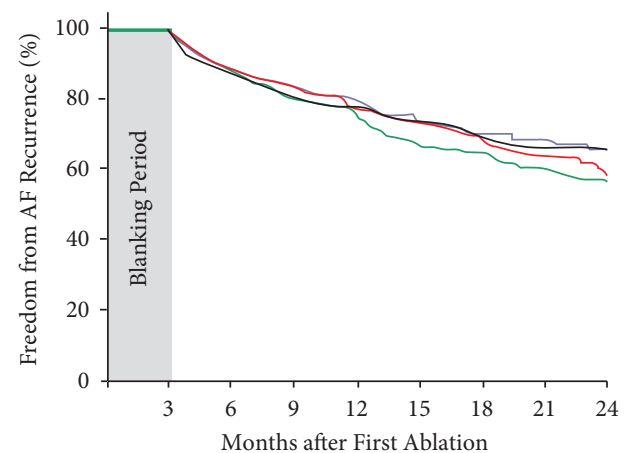

No. At Risk

Age $<53 \quad 584 \quad 457 \quad 342 \quad \begin{array}{lllllllll}286 & 235 & 187 & 153 & 133 & 115\end{array}$ $\begin{array}{lllllllllll}\text { Age 53-61 } & 630 & 481 & 357 & 288 & 240 & 197 & 169 & 139 & 113\end{array}$ $\begin{array}{llllllllll}\text { Age 61-67 } & 594 & 454 & 318 & 249 & 206 & 172 & 146 & 129 & 104\end{array}$

Age $\geq 67 \quad 726 \quad 547 \quad 416 \quad 321 \quad 272 \quad 202 \quad 166 \quad 135 \quad 109$

$$
\begin{aligned}
& \text { Group } \\
& \text { Age }<53 \quad \text { Age 61-67 }
\end{aligned}
$$

(a)

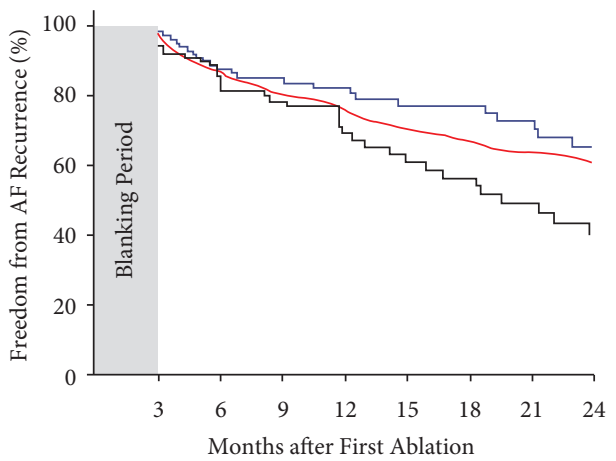

No. At Risk

$\begin{array}{llllllllll}\text { Age } \leq 40 & 131 & 106 & 75 & 62 & 51 & 39 & 36 & 31 & 24\end{array}$

$\begin{array}{llllllllll}\text { Age 41-74 } & 2281 & 1746 & 1294 & 1036 & 863 & 690 & 575 & 487 & 403\end{array}$

$\begin{array}{llllllllll}\text { Age 61-67 } & 122 & 87 & 64 & 46 & 39 & 29 & 23 & 18 & 14\end{array}$

Group

- Age $\leq 40$

- Age 41-74

- Age $\geq 75$

FIGURE 2: Freedom from AF recurrence in the 1STOP population. (a) Freedom from AF recurrence analyzed in four separate quartiles according to age. Overall adjusted $p$ value from Log-Rank Test $=1.000$. The mean follow-up duration was $15.3 \pm 14.7$ in the whole population with no significant difference among the groups $(16.1 \pm 14.9,15.6 \pm 15.2,14.9 \pm 15.0,14.8 \pm 13.9$ in the four groups from the youngest to the oldest). (b) Freedom from AF recurrence analyzed in three groups according to age (age $\leq 40,41<$ age $<74$, age $\geq 75$ ). Overall adjusted $p$ value from Log-Rank Test $=0.113$. The mean follow-up duration in the three age's group was $16.2 \pm 15.3,15.3 \pm 14.7$, and $13.7 \pm 14.5$ in the age $\leq 40,41<$ age $<74$, and age $\geq 75$ groups, respectively $(p=1.000)$.

\section{Discussion}

In this current evaluation of the 1STOP analysis, a population of 2,534 patients with AF who were treated by CBA using a PVI strategy of ablation were examined across quartiles of age, including (1) $<53$ years, (2) $\geq 53$ and $<61$ years, (3) $\geq 61$ and $<67$ years, and $(4) \geq 67$ years. Ten percent of the study population were only mildly symptomatic, and ablation was indicated on the basis of a clinical evaluation, according to the clinical practice of the center and taking into account the AF burden. Among the four age groups, there were no statistical differences with regard to acute procedural parameters or procedure-related complications, which were relatively low at $4.1 \%$. At the 12 -month followup, freedom from AF recurrence was 79.2\%, 77.4\%, 76.8\%, and $75.2 \%(p=0.21)$, respectively (with increasing age). Age did not result in a significant predictor of $\mathrm{AF}$ recurrence 
TABLE 4: Univariate analysis to investigate AF predictors. Baseline characteristics resulting in differences between groups $(p<0.10)$ were tested and are presented.

\begin{tabular}{|c|c|c|c|c|}
\hline \multirow{2}{*}{ Variable } & \multicolumn{2}{|l|}{ Univariate } & \multicolumn{2}{|l|}{ Multivariate } \\
\hline & Hazard ratio $(\mathrm{HR})(95 \% \mathrm{CI})$ & $p$ value & Hazard ratio (HR) $(95 \% \mathrm{CI})$ & $p$ value \\
\hline Group (age $<53$ vs. Others) & $0.86(0.70-1.06)$ & 0.168 & & \\
\hline Group (age $\geq 53$ and $<61$ vs. Others) & $1.01(0.83-1.23)$ & 0.891 & & \\
\hline Group (age $\geq 61$ and $<67$ vs. Others) & $0.92(0.75-1.14)$ & 0.459 & & \\
\hline Group (age $\geq 67$ vs. Others) & $1.19(0.99-1.43)$ & 0.061 & & \\
\hline Gender (male) & $0.90(0.75-1.09)$ & 0.272 & & \\
\hline Body Mass index (continuous) & $1.00(0.97-1.02)$ & 0.894 & & \\
\hline Type of AF-persistent & $1.60(1.33-1.92)$ & $<.001$ & $1.38(1.24-1.50)$ & $<0.001$ \\
\hline Number of tested AAD 2+ & $1.22(1.02-1.46)$ & 0.030 & & \\
\hline NYHA (categorical) & $0.86(0.67-1.11)$ & 0.250 & & \\
\hline History of stroke/TIA & $1.23(0.82-1.83)$ & 0.321 & & \\
\hline Hypertension & $1.26(1.06-1.50)$ & 0.008 & & \\
\hline Any valve diseases & $1.17(0.77-1.80)$ & 0.462 & & \\
\hline $\mathrm{CHA}_{2} \mathrm{DS}_{2}-\mathrm{VASc}$ (continuous) & $1.09(1.02-1.17)$ & 0.012 & $1.11(1.03-1.20)$ & 0.006 \\
\hline Ischemic cardiopathy & $1.00(0.69-1.45)$ & 0.987 & & \\
\hline Hypertensive cardiomiopathy & $1.11(0.88-1.40)$ & 0.364 & & \\
\hline Left atrial area $\left(\mathrm{cm}^{2}\right)$ (continuous) & $1.01(0.99-1.04)$ & 0.166 & & \\
\hline Left atrial area $\left(\mathrm{cm}^{2}\right)>21$ & $1.22(0.94-1.57)$ & 0.135 & & \\
\hline Mitral regurgitation (categorical) & $0.91(0.78-1.04)$ & 0.173 & & \\
\hline
\end{tabular}

In bold are presented variables with a $p<0.10$ in the univariate model, which were used in the multivariate model. In the multivariate model, the only independent predictors of $\mathrm{AF}$ recurrence were persistent $\mathrm{AF}$ and $\mathrm{CHA}_{2} \mathrm{DS}_{2}-\mathrm{VASc}$.

during follow-up; however, a trend toward higher AF recurrences rates in patients $\geq 67$ years was observed.

4.1. AF Ablation in Young and Old Patients. The efficacy and safety of AF ablation in younger and older populations have not been deeply investigated. Despite the increasing experience of operators and significant advancements in technological support, safety is still a remarkable issue for $\mathrm{AF}$ ablation [25-27]. Moreover, low rates of complications are hardly acceptable in relation to the treatment of an arrhythmia, which is generally considered a "non-lifethreatening" illness (particularly in very young patients). On the other hand, the worldwide population is constantly aging, and the prevalence of AF is higher in the elderly [1-5]. Therefore, many elderly patients could theoretically be good candidates for AF ablation. Although AF is associated with aging and cardiopulmonary pathologies, it is possible to observe it in young subjects, without structural heart disease. This patient subset lacks solid data on the efficacy and safety of the ablative procedures with both RFA and cryoablation. However, encouraging data have come from small sample studies showing positive feedback on recurrence of $\mathrm{AF}$ and complication rates of ablative procedures in the young, regardless of the ablation catheter [28-31]. Generally speaking, large studies exploring the safety and efficacy of AF ablation according to patients' age are still lacking.

The high number of comorbidities in the elderly strongly limits the use of antiarrhythmic therapy. Therefore, catheter ablation could represent a definitive solution for maintaining sinus rhythm in the elderly. However, the limited experiences available in the literature cannot scientifically support the wide use of ablation in the elderly. Some studies have explored the effects of RFA in the elderly [32-34]. Even if those studies are not homogeneous for the number of patients included, types of arrhythmia, distribution, and classes of age, an overall evaluation of those papers seems to suggest similar rates of success and complications between older and younger patients [32,33]. In a small single-center retrospective analysis conducted on patients $\geq 75$ years undergoing RFA, Metzner and colleagues [35] reported an incidence of $5.8 \%$ for major and $19 \%$ for minor complications. In the same report, the authors showed that after a single ablative procedure only $38 \%$ of patients were in stable rhythm after a mean follow-up of $37 \pm 20$ months ( $46 \%$ of paroxysmal AF patients, $31 \%$ of persistent $\mathrm{AF}$ patients, and $10 \%$ of long-standing AF patients).

CBA emerged as a promising strategy to cure AF with high procedural success rates, high durability of PVI, $[36,37]$, and good short- and long-term success rates with an acceptable incidence of complications in both paroxysmal and persistent AF [38-40]. Also, the Fire and Ice trial provided evidence for a noninferiority efficacy of cryoballoon versus RFA for PVI in patients with paroxysmal AF [18]. Nevertheless, patients over 75 years were not included in the trial [40]. More recently, Heeger and colleagues (in a multicenter study) compared the effects of cryoballoon ablation in 104 patients $\geq 75$ years and in 104 propensity score-matched patients $<75$ years [41]. The authors reported comparable safety, short-term efficacy, and long-term efficacy in both groups. However, procedure-related major complications were reported in $6.7 \%$ of patients of both groups. Furthermore, in another study, no statistically significant differences in complication and recurrence rates were found by comparing a group of patients aged $\geq 75$ with a group of patients aged $<75$ both treated with PVI by CBA for paroxysmal or persistent AF [42]. Other single-center or multicenter experiences provide further evidence for the safety and efficacy of CBA in elderly patients [43-47]. In 
summary, although positive and encouraging data on efficacy and safety in particularly old patients exist, they are limited and mainly based on small samples. Our analysis (including 2,534 patients) could represent an important overview highlighting CBA efficacy and safety according to the patent's age and confirming high safety and efficacy levels both in the elderly and in young patients.

4.2. Influence of Age on AF Cryoablation Efficacy. Our data, coming from a large real-world multicenter prospective project, seems to suggest similar outcomes of CBA in the four groups of patients, with no statistically significant differences in terms of AF recurrences between the quartiles. This observation was further confirmed by the univariate and multivariate analysis. Particularly, age did not result in being a significant predictor of AF recurrence in both univariate and multivariate analyses. However, a nonstatistically significant trend toward higher AF recurrences rates in patients $\geq 67$ years was observed. Even if this is only "a trend," we can speculate that such a result could be easily explained by the greater degree of "atrial cardiomyopathy" as well as a cumulative greater number of patients suffering from persistent and long-standing persistent AF in the elderly. Moreover, when the sample was divided into the three groups of patients (very young, middle aged, and elderly, respectively), significant statistical differences were obtained in the AF recurrence rates. More precisely, the Kaplan-Meier curves showed a similar recurrence trend in the three groups up to 12 months after the index procedure, but after this period, there is a significant increase in the recurrence rate in patients with age greater than 74 years when compared with the other two groups. It is known that aging involves a negative electro-anatomical remodeling of the atrium, so the patients are more vulnerable to triggering and maintaining AF. However, such results, balancing risk/benefit ratio, provide further scientific evidence to encourage the wider use of CBA both in the elderly and in the young patients, with symptomatic recurrent AF.

Another interesting point to be underlined is the lower rates of repeat procedures in patients above 67 years, despite a comparable incidence of arrhythmia recurrences in the same group. This may reflect a higher threshold to indicate a repeat procedure in the elderly, in the daily practice. The high levels of safety for cryoballoon ablation even in the elderly, as demonstrated by our paper, could encourage in future wider indications for repeat procedures even in these patient groups.

\subsection{Safety and Procedural Outcomes of Cryoablation. As} already mentioned, safety may be an important issue about AF ablation even nowadays and particularly in younger or older patients. Our analysis clearly demonstrates that procedure-related complications rates were very low and similar in the four different classes of age. Therefore, the safety of CBA is not influenced by the patient's age. The analysis in very young (age $\leq 40$ years) or very old patients (age $\geq 75$ years) confirmed similar complication rates in comparison to the rest of the population. In the quartile analysis, a slight but significantly lower percentage of isolated PVs in younger patients was observed. In a real-world observational study, it is not so easy to explain such a result that comes from a "reallife observation". Also, slightly superior ablative times were observed both in the younger quartile and in the quartile of patients between 53 and 61 years. However, the quartile comparison showed no other statistically significant differences in procedural data. The possibility of offering an equal procedural performance to the fragile oldest patients or younger patients could represent a significant benefit.

\section{Conclusion}

Our large and multicenter real-world prospective registry showed high safety levels for CBA at different ages. Procedural performance indicators were similar at different ages, and complication rates were low and not related to the patient's age. Even procedural efficacy was not influenced by age. The slightly higher rates of AF recurrences should be considered in very old candidates ( $\geq 75$ years), which occurred in a mid-term follow-up period.

Such results provide further scientific evidence for the use of CBA even in younger or older populations.

\section{Limitations}

We acknowledge that the median follow-up time of this analysis is 15 months and that a longer follow-up time can be needed to assess and confirm our results over time.

The percentage of the female sex is low, especially in the younger cohort of patients. This reflects the clinical practice, as per the nature of this project.

Some baseline characteristics of the study populations are different in the various groups analyzed. We believe that this limitation deals with the intrinsic nature of the registry. However, even if we do not think that those differences significantly influence the study results, they have to be taken into account.

Data on PVI durability and predominant extra PVtriggers according to patients' age were not discussed in this analysis.

\section{Data Availability}

All data are included in the Italian ClinicalService ${ }^{\circledR}$.

\section{Conflicts of Interest}

The authors declare that they have no conflicts of interest.

\section{Acknowledgments}

The authors would like to thank Hae Lim and Antonio Gianluca Robles for their help in the preparation of the manuscript.

\section{Supplementary Materials}

Supplementary Figure 1: 2534 patients enrolled divided into four quartiles according to patients age. Moreover, 
subgroups of "younger" patients (age $\leq 40$ years) and older patients (age $>74$ years) were identified. (Supplementary Materials)

\section{References}

[1] D. M. Lloyd-Jones, T. J. Wang, E. P. Leip et al., "Lifetime risk for development of atrial fibrillation," Circulation, vol. 110, no. 9, pp. 1042-1046, 2004.

[2] S. Björck, B. Palaszewski, L. Friberg, and L. Bergfeldt, "Atrial fibrillation, stroke risk, and warfarin therapy revisited: a population-based study," Stroke, vol. 44, no. 11, pp. 3103-3108, 2013.

[3] M. Haim, M. Hoshen, O. Reges, Y. Rabi, R. Balicer, and M. Leibowitz, "Prospective national study of the prevalence, incidence, management and outcome of a large contemporary cohort of patients with incident non-valvular atrial fibrillation," Journal of American Heart Association, vol. 4, no. 1, p. e001486, 2015.

[4] S. S. Chugh, R. Havmoeller, K. Narayanan et al., "Worldwide epidemiology of atrial fibrillation," Circulation, vol. 129, no. 8, pp. 837-847, 2014.

[5] M. Zoni-Berisso, F. Lercari, T. Carazza, and S. Domenicucci, "Epidemiology of atrial fibrillation: European perspective," Clinical Epidemiology, vol. 6, pp. 213-220, 2014.

[6] D. G. Jones, S. K. Haldar, W. Hussain et al., "A randomized trial to assess catheter ablation versus rate control in the management of persistent atrial fibrillation in heart failure," Journal of the American College of Cardiology, vol. 61, no. 18, pp. 1894-1903, 2013.

[7] J. Cosedis Nielsen, A. Johannessen, P. Raatikainen et al., "Radiofrequency ablation as initial therapy in paroxysmal atrial fibrillation," New England Journal of Medicine, vol. 367, no. 17, pp. 1587-1595, 2012.

[8] D. J. Wilber, C. Pappone, P. Neuzil et al., "Comparison of antiarrhythmic drug therapy and radiofrequency catheter ablation in patients with paroxysmal atrial fibrillation," JAMA, vol. 303, no. 4, pp. 333-340, 2010.

[9] H. Calkins, M. R. Reynolds, P. Spector et al., "Treatment of atrial fibrillation with antiarrhythmic drugs or radiofrequency ablation," Circulation: Arrhythmia and Electrophysiology, vol. 2, no. 4, pp. 349-361, 2009.

[10] L. Mont, F. Bisbal, A. Hernández-Madrid et al., "Catheter ablation vs. antiarrhythmic drug treatment of persistent atrial fibrillation: a multicentre, randomized, controlled trial (SARA study)," European Heart Journal, vol. 35, no. 8, pp. 501-507, 2014.

[11] C. A. Morillo, A. Verma, S. J. Connolly et al., "Radiofrequency ablation vs antiarrhythmic drugs as first-line treatment of paroxysmal atrial fibrillation (RAAFT-2)," JAMA, vol. 311, no. 7, pp. 692-700, 2014.

[12] O. M. Wazni, N. F. Marrouche, D. O. Martin et al., "Radiofrequency ablation vs antiarrhythmic drugs as first-line treatment of symptomatic atrial fibrillation," JAMA, vol. 293, no. 21, pp. 2634-2640, 2005.

[13] D. L. Packer, D. B. Mark, R. A. Robb et al., "Effect of catheter ablation vs antiarrhythmic drug therapy on mortality, stroke, bleeding, and cardiac arrest among patients with atrial fibrillation," JAMA, vol. 321, no. 13, pp. 1261-1274, 2019.

[14] M. Haïssaguerre, P. Jaï, D. C. Shah et al., "Spontaneous initiation of atrial fibrillation by ectopic beats originating in the pulmonary veins," New England Journal of Medicine, vol. 339, no. 10, pp. 659-666, 1998.
[15] E. Arbelo, J. Brugada, G. Hindricks et al., "Atrial Fibrillation Ablation Pilot Study Investigators. The atrial fibrillation ablation pilot study: a European Survey on Methodology and results of catheter ablation for atrial fibrillation conducted by the European Heart Rhythm Association," European Heart Journal, vol. 35, no. 22, pp. 1466-1478, 2014.

[16] H. Calkins, K. H. Kuck, R. Cappato et al., "2012 HRS/EHRA/ ECAS expert consensus statement on catheter and surgical ablation of atrial fibrillation: recommendations for patient selection, procedural techniques, patient management and follow-up, definitions, endpoints, and research trial design: a report of the heart rhythm society (hrs) task force on catheter and surgical ablation of atrial fibrillation. Developed in partnership with the European heart rhythm association (ehra), a registered branch of the European society of cardiology (ESC) and the European cardiac arrhythmia society (ecas); and in collaboration with the American college of cardiology (acc), American heart association (aha), the asia pacific heart rhythm society (aphrs), and the society of thoracic surgeons (sts). Endorsed by the governing bodies of the American college of cardiology foundation, the American heart association, the European cardiac arrhythmia society, the European heart rhythm association, the society of thoracic surgeons, the asia pacific heart rhythm society, and the heart rhythm society," Europace, vol. 14, no. 4, pp. 528-606, 2012.

[17] A. Luik, A. Radzewitz, M. Kieser et al., "Cryoballoon versus open irrigated radiofrequency ablation in patients with paroxysmal atrial fibrillation," Circulation, vol. 132, no. 14, pp. 1311-1319, 2015.

[18] K.-H. Kuck, J. Brugada, A. Fürnkranz et al., "Cryoballoon or radiofrequency ablation for paroxysmal atrial fibrillation," New England Journal of Medicine, vol. 374, no. 23, pp. 2235-2245, 2016.

[19] P. Kirchhof, S. Benussi, D. Kotecha et al., "2016 ESC Guidelines for the management of atrial fibrillation developed in collaboration with EACTS," European Heart Journal, vol. 37, no. 38, pp. 2893-2962, 2016.

[20] L. Padeletti, A. Curnis, C. Tondo et al., "Pulmonary vein isolation with the cryoballoon technique: feasibility, procedural outcomes, and adoption in the real world," Pacing and Clinical Electrophysiology, vol. 40, no. 1, pp. 46-56, 2017.

[21] C. Tondo, S. Iacopino, P. Pieragnoli et al., "Pulmonary vein isolation cryoablation for patients with persistent and longstanding persistent atrial fibrillation: clinical outcomes from the real-world multicenter observational project," Heart Rhythm, vol. 15, no. 3, pp. 363-368, 2018.

[22] G. Stabile, C. Tondo, A. Curnis et al., "Efficacy of cryoballoon ablation in patients with paroxysmal atrial fibrillation without time to pulmonary vein isolation assessment," International Journal of Cardiology, vol. 272, pp. 118-122, 2018.

[23] W. Su, R. Kowal, M. Kowalski et al., "Best practice guide for cryoballoon ablation in atrial fibrillation: the compilation experience of more than 3000 procedures," Heart Rhythm, vol. 12, no. 7, pp. 1658-1666, 2015.

[24] E. Bertaglia, G. Stabile, G. Senatore et al., "Predictive value of early atrial tachyarrhythmias recurrence after circumferential anatomical pulmonary vein ablation," Pacing and Clinical Electrophysiology, vol. 28, no. 5, pp. 366-371, 2005.

[25] G. Steinbeck, M. F. Sinner, M. Lutz, M. Müller-Nurasyid, S. Kääb, and H. Reinecke, "Incidence of complications related to catheter ablation of atrial fibrillation and atrial flutter: a nationwide in-hospital analysis of administrative data for Germany in 2014," European Heart Journal, vol. 39, no. 45, pp. 4020-4029, 2018. 
[26] R. Cappato, H. Calkins, S.-A. Chen et al., "Updated worldwide survey on the methods, efficacy, and safety of catheter ablation for human atrial fibrillation," Circulation: Arrhythmia and Electrophysiology, vol. 3, no. 1, pp. 32-38, 2010.

[27] L. Calò and L. Sciarra, "Heat or cold: different questions, same doubts," Heart Rhythm, vol. 14, no. 1, pp. 17-18, 2017.

[28] L. Allam, R. Samir, and A. N. Ali, "Clinical outcomes of catheter ablation of paroxysmal atrial fibrillation in very young population compared to older population: a prospective study," The Egyptian Heart Journal, vol. 71, no. 1, p. 11, 2019.

[29] J. Chen, H. Wang, M. Zhou, and L. Zhao, "Catheter ablation for lone atrial fibrillation in individuals aged under 35 years," Cardiology in the Young, vol. 29, no. 5, pp. 643-648, 2019.

[30] D. Moran, V. De Regibus, C. de Asmundis et al., "Second generation cryoballoon ablation for atrial fibrillation in young adults: midterm outcome in patients under 40 years of age," EP Europace, vol. 20, no. 2, pp. 295-300, 2018.

[31] M. Wójcik, A. Berkowitsch, S. Zaltsberg et al., "Cryoballoon ablation in young patients with lone paroxysmal atrial fibrillation," Revista Española de Cardiología, vol. 67, no. 7, pp. 558-563, 2014.

[32] K. Letsas, N. Karamichalakis, K. Vlachos et al., "Managing atrial fibrillation in the very elderly patient: challenges and solutions," Vascular Health and Risk Management, vol. 11, pp. 555-562, 2015.

[33] K. Nademanee, M. Amnueypol, F. Lee et al., "Benefits and risks of catheter ablation in elderly patients with atrial fibrillation," Heart Rhythm, vol. 12, no. 1, pp. 44-51, 2015.

[34] G. Stabile, E. Bertaglia, C. Pappone et al., "Influence of age and gender on complications of catheter ablation for atrial fibrillation," Journal of Atrial Fibrillation, vol. 7, no. 6, p. 1197, 2015.

[35] I. Metzner, E. Wissner, R. R. Tilz et al., "Ablation of atrial fibrillation in patients $\geq 75$ years: long-term clinical outcome and safety," Europace, vol. 18, no. 4, pp. 543-549, 2016.

[36] C.-H. Heeger, E. Wissner, S. Mathew et al., "Once isolated, always isolated?" Circulation: Arrhythmia and Electrophysiology, vol. 8, no. 5, pp. 1088-1094, 2015.

[37] V. Y. Reddy, L. Sediva, J. Petru et al., "Durability of pulmonary vein isolation with cryoballoon ablation: results from the Sustained PV Isolation with Arctic Front Advance (SUPIR) study," Journal of Cardiovascular Electrophysiology, vol. 26, no. 5, pp. 493-500, 2015.

[38] C.-H. Heeger, E. Wissner, M. Knöll et al., "Three-year clinical outcome after 2nd-generation cryoballoon-based pulmonary vein isolation for the treatment of paroxysmal and persistent atrial fibrillation-A 2-center experience," Circulation Journal, vol. 81, no. 7, pp. 974-980, 2017.

[39] G.-B. Chierchia, G. Di Giovanni, G. Ciconte et al., "Secondgeneration cryoballoon ablation for paroxysmal atrial fibrillation: 1-year follow-up," Europace, vol. 16, no. 5, pp. 639-644, 2014.

[40] A. Fürnkranz, J. Brugada, J.-P. Albenque et al., "Rationale and Design of FIRE AND ICE: a multicenter randomized trial comparing efficacy and safety of pulmonary vein isolation using a cryoballoon versus radiofrequency ablation with 3Dreconstruction," Journal of Cardiovascular Electrophysiology, vol. 25, no. 12, pp. 1314-1320, 2014.

[41] C.-H. Heeger, B. Bellmann, T. Fink et al., "Efficacy and safety of cryoballoon ablation in the elderly: a multicenter study," International Journal of Cardiology, vol. 278, pp. 108-113, 2019.
[42] V. Tscholl, T. Lin, A. K.-A. Lsharaf et al., "Cryoballoon ablation in the elderly: one year outcome and safety of the second-generation $28 \mathrm{~mm}$ cryoballoon in patients over 75 years old," EP Europace, vol. 20, no. 5, pp. 772-777, 2018.

[43] J.-P. Abugattas, S. Iacopino, D. Moran et al., "Efficacy and safety of the second generation cryoballoon ablation for the treatment of paroxysmal atrial fibrillation in patients over 75 years: a comparison with a younger cohort," EP Europace, vol. 19, no. 11, pp. 1798-1803, 2017.

[44] A. Pott, M. Messemer, K. Petscher et al., "Clinical outcome of 2nd generation Cryoballoon pulmonary vein isolation in patients over 75 years of age," Journal of Cardiology, vol. 69, no. 1, pp. 24-29, 2017.

[45] J. Zhang, Z. Ren, S. Wang et al., "Efficacy and safety of Cryoballoon ablation for Chinese patients over 75 years old: a comparison with a younger cohort," Journal of Cardiovascular Electrophysiology, vol. 30, no. 12, pp. 2734-2742, 2019.

[46] A. Abdin, K. Yalin, E. Lyan et al., "Safety and efficacy of Cryoballoon ablation for the treatment of atrial fibrillation in elderly patients," Clinical Research in Cardiology, vol. 108, no. 2, pp. 167-174, 2019.

[47] S. Hartl, U. Dorwarth, J. Pongratz et al., "Impact of age on the outcome of cryoballoon ablation as the primary approach in the interventional treatment of atrial fibrillation: insights from a large all-comer study," Journal of Cardiovascular Electrophysiology, vol. 32, no. 4, pp. 949-957, 2021. 